\title{
Effect of Heat Energy Input on Electrochemical Properties of Solution-Annealed Super-Duplex Stainless Steel UNS S 32750 Laser Welding
}

\author{
Changwon Sung ${ }^{1}$, Byung-Hyun Shin ${ }^{2, *}$, and Wonsub Chung ${ }^{3, *}$ \\ ${ }^{1}$ Kowel Corporation, Yangsan, Republic of Korea \\ ${ }^{2}$ Cold Rolling Production Engineering Team, Hyungdai steel, Dangjin-Si 31719, Republic of Korea \\ ${ }^{3}$ School of Materials Science and Engineering, Pusan National University, Busan 46241, Republic of \\ Korea \\ *E-mail: lemonhouse947@nate.com \& wschung1@pusan.ac.kr
}

Received: 2 December 2021 / Accepted: 17 January 2022 / Published: 2 February 2022

\begin{abstract}
Super duplex stainless steel (SDSS) exhibits a high corrosion resistance in seawater because of the combination of austenite and ferrite present. Laser welding breaks the balance between austenite and ferrite owing to changes in the microstructure during the ferritization. Therefore, the corrosion resistance of the weld zone on SDSS depends on the heat energy input. In this study, we examined the electrochemical behavior of SDSS after laser welding at different heat energy inputs. It was observed that laser welding reduced the corrosion resistance of SDSS, which depended on the heat energy input. The corrosion resistance of the surface of welded SDSS was determined by analyzing the open circuit potential, potentiodynamic polarization tests, critical pitting temperature (CPT), and electrochemical impedance spectroscopy. An increase in the heat energy input decreased the corrosion resistance and the thickness of SDSS and the passivation layer, respectively. However, after full penetration, the CPT of SDSS increased from 48 to $61^{\circ} \mathrm{C}$. The electrochemical properties of SDSS was affected by the surface reactivity and shape of the bead.
\end{abstract}

Keywords: electrochemical properties; laser welding; heat input energy; super-duplex stainless steel; solution annealing

\section{$\underline{\text { FULL TEXT }}$}

(C) 2022 The Authors. Published by ESG (www.electrochemsci.org). This article is an open access article distributed under the terms and conditions of the Creative Commons Attribution license (http://creativecommons.org/licenses/by/4.0/). 